\title{
PARÂMETROS INTERNACIONAIS DE DIREITOS HUMANOS REFERENTES À MIGRAÇÃO E A PROIBIÇÃO DE RETROCESSO: UMA ANÁLISE CRÍTICA DOS IMPACTOS DECORRENTES DA PORTARIA N. 666/2019
}

\author{
Urá Lobato Martins ${ }^{1}$ \\ Francisco Geraldo Matos Santos ${ }^{2}$
}

\section{RESUMO:}

O artigo analisa os impactos da Portaria $n^{\circ}$. 666/2019, considerando a conjuntura histórica, social e política que permeiam a publicação da norma. A pesquisa foi orientada pelas seguintes questões norteadoras: de que forma as normas internacionais de direitos humanos impedem a edição de atos normativos contrários aos direitos migratórios? Os crimes listados na Portaria n. 666/2019 são passíveis expulsão ou deportação? Quais são os direitos violados pela referida norma? Para tanto, utilizou-se o método hipotético-dedutivo, com pesquisa bibliográfica e documental, através de abordagem qualitativa. Ao final, será apresentada reflexão crítica sobre a pesquisa, propondo-se questionamentos para novas reflexões.

Palavras-chave: direitos humanos internacionais; migração; Portaria 666/2019; proibição de retrocesso social.

\section{INTERNATIONAL PARAMETERS OF HUMAN RIGHTS CONCERNING MIGRATION AND RETROCESS PROHIBITION: A CRITICAL ANALYSIS OF THE IMPACTS ARISING FROM ORDER N. 666/2019}

\begin{abstract}
:
The article analyzes the impacts of Ordinance n. 666/2019, considering the historical, social and political conjuncture that permeates the publication of the standard. The research was guided by the following guiding questions: How do international human rights norms prevent the editing of normative acts contrary to migratory rights? The crimes listed in Ordinance no. $666 / 2019$ are liable to expulsion or deportation? What rights are violated by this standard? Therefore, the hypothetical-deductive method was used, with bibliographic and documentary research, through a qualitative approach. At the end, a critical reflection on the research will be presented, proposing questions for further reflection.
\end{abstract}

Keywords: international human rights; migration; Ordinance 666/2019; ban on social setback.

\section{INTRODUÇÃO}

\footnotetext{
${ }^{1}$ Doutora em Políticas Públicas e Formação Humana pela UERJ. Mestra em Direitos Humanos pela UFPA. Advogada e Professora Universitária. Contato: uramartins@ig.com.br.

${ }^{2}$ Doutorando em Direito (PPGD/UFPA). Mestre em Ciência Política pelo PPGCP/UFPA. Especialista em Processo Penal e em Direito Público pela Faculdade Prof. Damásio de Jesus. Graduado em Direito. Docente do Ensino Superior. Assessor Jurídico na Prefeitura Municipal de Santa Izabel do Pará. Contato: fgeraldomatos@hotmail.com.
} 
Sabe-se que os direitos e garantias fundamentais constitucionais também se aplicam aos migrantes que estejam no país. Portanto, nosso direito brasileiro garante a todo migrante a inviolabilidade do direito à vida, à liberdade, à igualdade, à segurança e à propriedade, bem como o direito à liberdade de circulação.

É preciso esclarecer que a discricionariedade do Estado não é absoluta, pois há parâmetros internacionais de direitos humanos referentes à migração que não devem ser desprezados. Portanto, os Tratados que o Brasil decidiu ser signatário também vinculam a ordem interna, como ocorre no caso da Declaração Universal dos Direitos do Homem sendo, inclusive, considera uma norma de jus cogens -, a Convenção Americana sobre Direitos Humanos (Pacto de San José da Costa Rica) e a Convenção Relativa ao Estatuto dos Refugiados de 1951 (Convenção de Genebra).

Além disso, a Lei de Migração no $13.445 / 2017$, em seu art. $3^{\circ}$ relaciona os princípios e diretrizes que regem a política migratória brasileira, merecendo destaque a questão da universalidade, indivisibilidade e interdependência dos direitos humanos; bem como o repúdio a qualquer forma de discriminação ou deportação coletiva.

Porém, no dia 26 de julho de 2019 foi publicada a Portaria n. 666, assinada pelo Ministro da Justiça Sérgio Moro, dispondo sobre o impedimento de ingresso, a repatriação e a deportação sumária de pessoa perigosa ou que tenha praticado ato contrário aos princípios e objetivos dispostos na Constituição Federal. Através deste ato infralegal foi determinado que a pessoa notificada tem 48 horas para deixar o país ou apresentar defesa, sendo que são considerados perigosos para o Brasil os suspeitos de envolvimento com terrorismo, crime organizado, tráfico de drogas, pornografia, exploração sexual e casos de violência em estádios. Além disso, a suspeita pode decorrer de troca de informações com serviços de inteligência de outros países, ordens judiciais e sentenças condenatórias.

Com efeito, a referida Portaria acabou inovando na ordem jurídica, ferindo normas de direito internacional, normas constitucionais e legais. Diante disso, o artigo analisa os impactos da Portaria n 666/2019, considerando a conjuntura histórica, social e política que permeiam a publicação da norma, bem como a violação ao Princípio da Proibição de Retrocesso Social.

Cabe ressaltar que no dia 05 de agosto de 2019 a Procuradoria Federal dos Direitos do Cidadão do Ministério Público Federal (MPF) recomendou ao Ministro da Justiça Sérgio 
Moro a suspensão imediata da Portaria n. 666, com a consequente revogação de seus efeitos, segundo o argumento de que tal portaria extrapola sua competência regulamentadora, além de violar o arcabouço jurídico nacional e internacional sobre o tema. O MPF fixou o prazo de 5 (cinco) dias para manifestação, sob pena de adoção das medidas judiciais pertinentes (MPF, 2019).

A pesquisa foi orientada pelas seguintes questões norteadoras: de que forma as normas internacionais de direitos humanos impedem a edição de atos normativos contrários aos direitos migratórios? Os crimes listados na Portaria n. 666/2019 são passíveis expulsão ou deportação? Quais são os direitos violados pela referida norma? Para tanto, utilizou-se o método hipotético-dedutivo, com pesquisa bibliográfica e documental, através de abordagem qualitativa.

\section{CONTEXTUALIZANDO: UMA ANÁliSE DA CONJUNTURA HISTÓRICA, SOCIAL E POLÍtiCA QUE PERMEIAM A PUBLICAÇÃO DA PORTARIA N. $666 / 2019$}

Para Benhabib (2012) a imigração gera o confronto entre princípios que representam os alicerces do sistema moderno, pois, por um lado, os indivíduos possuem o direito de atravessar fronteiras (motivações econômicas, sociais, políticas, etc), por outro lado, é garantido o direito ao autogoverno.

De fato, como ensina Benhabib (2012), o corpo do imigrante passou a ser o local simbólico das contradições. Questões econômicas, ambientais, culturais e históricas "empurram" e "atraem" as pessoas ${ }^{3}$. Segundo a autora, temos obrigações morais com a humanidade, seja pelo fato de determinada economia ter prejudicado outro país, ou de determinada atividade industrial promover danos ambientais que ultrapassam os limites geográficos de um Estado. A questão, para a autora, é que há uma interdependência, sendo que também temos obrigações associativas, que decorrem de fatores históricos.

\footnotetext{
3 “A Organização Internacional sobre Migrações (OIM) estima que até setembro de 2015 ao menos 473.887 homens, mulheres e crianças fizeram a travessia do mar Mediterrâneo com destino à Europa, das quais 2.812 pessoas perderam a vida nessa travessia. A maior parte dos refugiados procede da Síria - o conflito que gerou mais refugiados nas últimas duas décadas. Atualmente, os conflitos decorrem menos de guerras envolvendo Estados e mais da violência associada ao colapso de Estados. De acordo com o Alto Comissariado da ONU para Refugiados (ACNUR), até 2015, mais de 59 milhões de pessoas foram forçadas a deixar o seu lugar de origem. O universo de refugiados hoje corresponde a uma população maior que a da Espanha ou da África do Sul." (PIOVESAN, 2018b, p. 307)
} 
Nessa linha, Piovesan (2018b) defende que o deslocamento forçado de pessoas já é um indicador de um padrão de violação de direitos humanos. Nos dias atuais, "aos refugiados políticos do passado aliam-se os refugiados econômicos do presente, na medida em que crescente fluxo de deslocamento de pessoas tem como razão a negação de direitos sociais básicos sob a forma da miséria, pobreza e exclusão social.” (PIOVESAN, 2018b, p. 307)

Um dos maiores dilemas da sociedade contemporânea é conseguir garantir efetividade aos direitos consagrados no plano interno e internacional. Herrera Flores (2009, p. 41) destaca que "o sistema de valores hegemônicos em nossos dias é majoritariamente neoliberal e, por conseguinte, coloca por cima as liberdades funcionais ao mercado e por baixo as políticas públicas de igualdade social, econômica e cultural.” Diante disso, Herrera Flores (2009, p. 31) ensina que é necessário "propor dinâmicas sociais de luta contra os processos hegemônicos de divisão do fazer humano".

Piovesan (2013), por sua vez, ressalta a necessidade de prosseguir no campo da responsabilidade estatal no que tange aos direitos humanos dos migrantes e refugiados, uma vez que que cabe ao Estado o dever de respeitar, proteger e implementar.

No caso do Brasil, muitas reformas legislativas (como ocorreu no caso da reforma trabalhista, dentre outras) estão sendo implementadas sem respeitar as normas internacionais que vinculam o Brasil, além de não considerar também os princípios e normas constitucionais vigentes. Isto sem falar nas possíveis alterações das normas previdenciárias.

Além disso, nosso atual Chefe do Poder Executivo adota medidas arbitrárias em diversos setores, como já ocorreu no caso da censura feita com relação a um comercial de um determinado banco; demissões motivadas por critérios ideológicos ${ }^{4}$; ignorância com relação aos dados científicos existentes sobre o desmatamento; desprezo pela causa indígena; interferência na autonomia universitária; cortes orçamentários que afetam a viabilidade de universidades, bem como prejudica pesquisas que necessitam de bolsas, revelando, assim, uma clara tendência autoritária e retrógrada. Tal postura reacionária vem sendo criticada por órgãos internacionais.

Sabe-se que o Estado Democrático de Direito foi resultado de lutas, retroceder causará danos irreparáveis aos direitos já consolidados. Com efeito, Losurdo (2006) ensina que o processo histórico que desencadeou a democracia não é absolutamente linear, pois teria ocorrido uma emancipação seguida de retrocesso - da mesma forma que Moyn (2010) quando

\footnotetext{
${ }^{4}$ Afastamento recente do diretor do Instituto Nacional de Pesquisas Espaciais (INPE), Sr. Ricardo Galvão.
} 
analisou o processo histórico dos direitos humanos -. Inicialmente, foram adquiridos direitos antes negados, porém, em seguida ocorreu uma privação dos direitos que os excluídos haviam garantido. Para ilustrar, o primeiro autor cita alguns exemplos:

\begin{abstract}
Afirmado na França na trilha da revolução de fevereiro de 1848, o sufrágio universal (masculino) é cancelado dois anos depois pela burguesia liberal, e logo depois é reintroduzido em decorrência não de um processo de amadurecimento do liberalismo, mas do golpe de Estado de Luís Napoleão, do qual se serve para a encenação do rito da aclamação plebiscitária. Nesse âmbito o exemplo mais clamoroso nos é fornecido pelos Estados Unidos. O fim da guerra da Secessão inaugura o período mais feliz da história dos afro-americanos, os quais agora conquistaram os direitos civis e políticos e entram a fazer parte dos organismos representativos. Mas, trata-se de uma espécie de breve intervalo da tragédia. $\mathrm{O}$ compromisso que ocorre em 1877 entre brancos do Norte e do Sul comporta para os negros a perda dos direitos políticos e, muitas vezes dos próprios direitos civis, como é testemunhado pelo regime de segregação racial e pela violência selvagem dos pogrom e dos linchamentos (LOSURDO, 2006, p. 358) (grifo nosso).
\end{abstract}

Piovesan (2018a, p. 271) destaca que "a progressividade dos direitos econômicos, sociais e culturais proíbe o retrocesso ou a redução de políticas públicas voltadas à garantia de tais direitos”. Logo, a cláusula de proibição do retrocesso social proíbe que Estados pratiquem retrocesso ou fiquem inertes no âmbito da implementação de direitos sociais.

Ao analisar o direito de resistência, Agamben (2004, p. 23-24) destaca que no projeto da Constituição Italiana, teria sigo introduzido o seguinte dispositivo "quando os poderes públicos violam as liberdades fundamentais e os direitos garantidos pela Constituição, a resistência a opressão é um direito e um dever do cidadão". No entanto, houve forte oposição e este dispositivo foi rejeitado. Mas o autor menciona que a Constituição da República Federal Alemã possui o art. 20 que legaliza o direito de resistência: "contra quem tentar abolir esta ordem [a constituição democrática], todos os alemães têm direito de resistência, se outros remédios não forem possíveis".

De fato, estamos passando por tempos sombrios de claros retrocessos em várias áreas do direito e da política pública, compete à academia analisar tais retrocessos e demonstrar, com base na doutrina e nas normas vigentes, se tais atos realmente merecem prosperar. $\mathrm{O}$ objeto desta pesquisa foi a questão migratória, em especial, a Portaria n. 666/2019, porém, precisávamos contextualizar a questão, pois como ensina Herrera Flores (2009, p. 30), "vivemos imersos em processos hierárquicos e desiguais que facilitam ou impedem a sua obtenção." 


\section{PARÂMETROS INTERNACIONAIS DE DIREITOS HUMANOS REFERENTES À MIGRAÇÃO: DA TENDÊNCIA INTERNACIONAL AO NACIONAL}

A mobilidade humana tem sido uma marca central de aprofundamento nas discussões proveniente do direito internacional contemporâneo, principalmente, porque além da intensificação dessa mobilidade, a proteção dos direitos humanos também passou a ser central nas questões interpretadas e reguladas por esse campo jurídico.

Há quem inclusive, como Ramos (2018) entende que a mobilidade humana representa tanto o fundamento social quanto o econômico da própria consolidação do direito internacional privado - embora não utilizemos nessa pesquisa, a discussão tendente a diferenciar ou não o direito internacional privado do público -.

Todavia, a inclusão da mobilidade humana no centro dessas discussões acaba por tornar ainda mais enfático a própria alteração - ou mutabilidade - das estruturas da sociedade internacional. De fato, há algumas categorias que tem sido alterada, principalmente, quando se compara sistemas jurídicos de democracias recém consolidas - ou ainda nem consolidadas -, que tiveram sua legislação relacional à essas temáticas, completamente enraizada em questões de contextos de ditaduras, como fora o caso do Brasil.

À guisa de análise, propomos a própria ideia de migração, que pela legislação brasileira pretérita, estava circunscrita à questão do estrangeiro, basta não olvidarmos a existência do revogado Estatuto do Estrangeiro (Lei $\mathrm{n}^{\circ}$ 6.815/80), elaborado antes da Constituição de 1988, em um regime - ditatorial - que prezava pela segurança nacional e relações econômicas, apenas.

Em 2017, no entanto, tal lei foi revogada pela então vigente, Lei da Migração - n $^{\circ}$ 13.445/2017. É importante frisar, de início, que não fora apenas a nomenclatura substituída: estrangeiro versus migrante, mas a própria sistemática protetiva dos direitos humanos que antes, talvez ficasse em segundo plano - ou mesmo, ignorada -.

A ideia de estrangeiro automaticamente nos remete à figura de alguém estranho ao país, e nem precisa utilizarmos o processo histórico de que este era aquele que praticava a mesma religião da cidade. A questão é que o estrangeiro, da forma como era tratado pelo Estatuto do Estrangeiro, embora a Constituição de 1988 tentasse promover a isonomia entre os nacionais - natos e naturalizados - e os não nacionais, ainda assim, a lei anterior não estava adequada a esses ditames, tampouco, às tendências protecionistas aos direitos humanos, 
mesmo porque, incluía no mesmo segmento, todos aqueles que não eram nacionais, ou seja, os estrangeiros.

Sobre o assunto, Guerra (2019, p. 416) afirma que

\begin{abstract}
No Brasil, até a edição da Lei n. 13.445, de 24 de maio de 2017, a matéria relativa à situação jurídica do estrangeiro estava prevista na Lei n. 6.815, de 19 de agosto de 1980, não havendo, até aquele momento, uma lei que tratasse de maneira específica sobre as migrações.

Impende assinalar que a Lei n. 6.815/80 foi concebida no período em que o Estado brasileiro era conduzido por militares e levava em conta aspectos voltados principalmente para a segurança nacional, apresentando-se como discriminatória e contrária aos fundamentos e princípios que norteiam a Carta Magna de 1988.
\end{abstract}

Levado não apenas pelo grande movimento migratório com que o Brasil tem vivenciado, mas também, o fato de que a legislação pretérita estava em descompasso com a Constituição de 1988, bem como, com a sistemática de proteção dos direitos humanos no sistema do direito internacional como um todo, é que o Congresso Nacional aprovou a atual Lei das Migrações, que fora proposta pelo Ministro das Relações Exteriores, senador Aloysio Nunes em 2013.

A nova sistemática não inclui todos os não nacionais no globo dos estrangeiros, como acontecia antes. Agora, a sistemática preza pela existência de migrantes, que advém da categoria migração, referindo-se a todo o movimento quer de entrada quer de saída de um país, região ou congênere. Aqui, portanto, estão incluídos os imigrantes - como sendo aqueles que pretendem com animus de permanência entrar em território brasileiro, não tendo a nacionalidade brasileira -, os emigrantes - como sendo aquele brasileiro que se estabelece temporariamente ou definitivamente no exterior -, o residente fronteiriço - pessoa nacional de país limítrofe ou apátrida que conserva a sua residência habitual em município fronteiriço de país vizinho -, visitantes - aquela pessoa não nacional que vem ao Brasil para estadias de curta duração, sem animus de permanência -, e os apátridas - aqueles sem a consideração de nacionalidade de algum Estado -.

Observa-se com a recente lei, que a pretensão almejada pelo Brasil, fora exatamente se adequar aos preceitos internacionais que ignoravam ou tentavam rechaçar entendimentos legislativos excludentes, que tinham no estrangeiro de fato, aquele que representava ameaça aos nacionais, alguém estranho.

A vertente protetiva do homem enquanto sujeito de direitos que deve ser resguardada em qualquer Estado, motivo pelo qual, o princípio da reciprocidade difundido outrora na Europa (França, Bélgica, Alemanha, Itália etc.) deixou de ser o defensivo em matéria de 
tratamento do não nacional. Hoje, reconhece-se aos não nacionais todos os direitos civis conferidos aos seus próprios nacionais.

Varella (2018) afirma, inclusive, que todos os Estados modernos procuram regulamentar, em seus respectivos ordenamentos jurídicos, as condições tanto de entrada, permanência, asilo e naturalização, quanto de deportação, expulsão e extradição do não nacional em seu território. E no caso do Brasil, hoje, essa regulamentação passou a ser feita nos moldes propostos pelo sentimento constitucional apresentado por Verdú (2004).

Agora, além do previsto no texto constitucional, o imigrante detém uma série de prerrogativas que antes eram conferidas apenas aos nacionais brasileiros. Guerra (2019, p. 423 ) pondera, como sendo preponderante com a inovação legislativa, fora a “desburocratização do processo de regularização imigratória, a institucionalização da política de vistos humanitários, a não criminalização por razões migratórias".

O imigrante, com a nova sistemática, é tido como sendo um sujeito de direitos - o problema é que esses direitos são ignorados na era da pós democracia, como bem ressalta Casara (2017). A nova lei tende a concretizar os ditames do próprio texto constitucional, que preza pelo princípio da igualdade entre os brasileiros e os não brasileiros, na medida em que de forma expressa tenta combater à discriminação, a xenofobia e outras condutas que possam violar direitos humanos.

Embora existam vozes contrárias a sistemática proposta pelo novel regulamento legislativo, o fato é que, conforme ensinam Asano e Timo (2017) a nova legislação migratória precisa observar ao menos cinco propostas: primeiro, o fato de ser indispensável a garantia dos direitos humanos das pessoas migrantes, sem que haja qualquer discriminação e dependência da sua situação migratória, segundo, a necessidade de haver a precisão quanto aos procedimentos de regularização migratória rápidos, efetivos e acessíveis como uma obrigação do Estado e um direito do migrante, terceiro, a própria não criminalização das migrações, incluindo o princípio de não detenção do migrante por razões que estejam vinculadas a sua própria situação migratória. Como quarta proposta, as autoras apontam o controle judicial e o acesso dos migrantes a recursos efetivos sobre todas as decisões do poder público que possam gerar vulneração de seus direitos. E por fim, elas argumentam a necessidade da "criação de uma instituição nacional autônoma, com um corpo profissional permanente e especializado e mecanismos de supervisão e controle social, responsável pela aplicação da lei”. 
O fato é que, a nível de parâmetros internacionais de direitos humanos, o Brasil, com a Lei de Migrações, observa-se no plano legislativo, uma inovação capaz de torná-lo um país condizente com as interpretações e discussões protetivas dos não nacionais. A questão, no entanto, é se no plano do Executivo, essa proposta vai ou não ser consolidada.

\section{ANÁlISE CRÍTICA DAS NOVAS CATEGORIAS INTRODUZIDAS PELA PORTARIA N. 666/2019}

\subsection{DELIMITANDO CONCEITOS: O QUE SERIA PESSOA PERIGOSA?}

A Portaria n. 666/2019, nos termos de seu art. $1^{\text {o }}$, teve o intuito de regular o impedimento de ingresso, a repatriação, a deportação sumária, a redução ou cancelamento do prazo de estada de pessoa perigosa para a segurança do Brasil ou de pessoa que tenha praticado ato contrário aos princípios e objetivos dispostos na Constituição Federal.

$\mathrm{O}$ art. $2^{\circ}$ da referida Portaria, por sua vez, define quem são as pessoas consideradas "perigosas" ou que tenham praticado ato contrário aos princípios e objetivos dispostos na Constituição Federal, sendo aqueles suspeitos de envolvimento em: terrorismo; grupo criminoso organizado ou associação criminosa armada ou que tenha armas à disposição; tráfico de drogas, pessoas ou armas de fogo; pornografia ou exploração sexual infantojuvenil; e torcida com histórico de violência em estádios (neste último caso, aplica-se somente durante a realização de evento esportivo que possa ser colocado em risco). Tais hipóteses poderão ser conhecidas e avaliadas pela autoridade migratória através dos seguintes instrumentos:

\footnotetext{
Art. $2^{\circ}(\ldots)$

$\S 1^{\circ}$ As hipóteses mencionadas nos incisos deste artigo poderão ser conhecidas e avaliadas pela autoridade migratória por meio de:

I - difusão ou informação oficial em ação de cooperação internacional;

II - lista de restrições exaradas por ordem judicial ou por compromisso assumido pela República Federativa do Brasil perante organismo internacional ou Estado estrangeiro;

III - informação de inteligência proveniente de autoridade brasileira ou estrangeira;

IV - investigação criminal em curso; e

$\mathrm{V}$ - sentença penal condenatória.
}

$\mathrm{O}$ art. $2^{\circ}, \S 4^{\circ}$, da Portaria mencionada determina que "para fins de aplicação do disposto no $\S 2^{\circ}$ do art. $7^{\circ}$ da Lei $n^{\circ} 9.474$, de 1997, considera-se perigosa para a segurança do Brasil a pessoa que se enquadre no rol do caput deste artigo”. (BRASIL, 2019) 
A questão é que o rol apresentado no primeiro artigo da Portaria trabalha com o conceito de suspeito, o que, por si só, fere o princípio da presunção de inocência. Além disso, a forma de enquadramento é muito subjetiva.

Giorgio Agamben (2007) ressalta como o racismo opera de forma excludente, sendo que alguns indivíduos podem gozar de uma forma de vida qualificada, enquanto outros podem simplesmente morrer ${ }^{5}$ pelo fato de sua vida estar vinculada apenas à vida nua, ou seja, a vida insacrificável do homo sacer, embora matável. Tal teoria pode ser aplicada ao caso em tela, pois também estamos tratando de discriminação. A Portaria n. 666 pode ser considerada, segundo a perspectiva agambeniana, como uma estratégia de biopolítica da modernidade, na busca de padrões impostos, controle de pessoas e fins de disciplinamento.

Logo, na modernidade o poder está pautado no conceito de uma vida nua, cuja salvaguarda fica dependente da submissão, sendo uma vida, no viés de Agamben, despida de todo atributo (CORREIA, 2014).

Sendo assim, aqueles que não se enquadram no que o Estado espera, serão automaticamente enquadrados como pessoas perigosas, sem sequer terem o direito constitucional de defesa resguardado, ofendendo a presunção de inocência. E, o que é mais grave, permitindo critérios subjetivos para averiguar suposto potencial de perigo, o que foge à lógica do Direito Penal que requer critérios concretos e objetivos, até para permitir a defesa.

Nessa linha, Jakobs e Meliá (2007, p. 37) destacam as seguintes tendências:

\begin{abstract}
(...) quem não quer privar o Direito penal do cidadão de suas qualidades vinculadas à noção de Estado de Direito - controle das paixões; reação exclusivamente frente a atos exteriorizados, não frente a meros atos preparatórios; a respeito da personalidade do delinquente no processo penal, etc. - deveria chamar de outra forma aquilo que tem que ser feito contra os terroristas, se não se quer sucumbir, isto é, deveria chamar Direito penal do inimigo, guerra contida. Portanto, o Direito Penal conhece dois polos ou tendências em suas regulações. Por um lado, o tratamento com o cidadão, esperando-se até que se exteriorize sua conduta para reagir, com o fim de confirmar a estrutura normativa da sociedade, e por outro, o tratamento com o inimigo, que é interceptado já no estado prévio, a quem se combate por sua periculosidade. (grifo nosso)
\end{abstract}

Dessa forma, Jakobs e Meliá (2007) ensinam que a concepção de Direito Penal do Inimigo é orientada para considerar que o cidadão deve ter determinados direitos e deve haver um direito para o outro direito para o inimigo (aquele que não cumpre as ordens do sistema).

\footnotetext{
${ }^{5}$ Não podemos esquecer que a ideia de morte para Agamben (2007) não se refere exclusivamente a morte em paralelo ao oposto de vida. A proposta da filosofia do autor, refere-se também a noção de morte social, morte política, morte cultural, ou seja, a ideia da própria marginalização social e penal que acaba por inferir, nesse contexto, a que a pessoa "suspeita" está enquadrada.
} 
Nesse contexto, a mídia também pode interferir, gerando em alguns casos sensacionalismo e/ou temor psicológico, o que pode gerar no pensamento coletivo um sentimento de repulsa e discriminação com relação ao migrante.

Sendo assim, os que estão categorizados na nova Portaria n. 666 não poderiam gozam dos mesmos direitos dos cidadãos. Ocorre que "o Direito Penal do cidadão é o Direito de todos, o Direito Penal do inimigo é daqueles que o constituem contra o inimigo: frente ao inimigo, é só a coação física, até chegar à guerra”. (JAKOBS, MELIÁ, 2007, p. 30)

Portanto, ao invés de proteger o não nacional, o Estado rotula sujeitos como pessoas perigosas, desconsiderando o ser enquanto sujeito de direito, ferindo parâmetros de direito internacional sobre direitos humanos.

\subsection{DEPORTAÇÃO SUMÁRIA: UMA ANÁLISE DOS DIREITOS VIOLADOS ATRAVÉS DA NOVA CATEGORIA INTRODUZIDA PELA PORTARIA Nº66/2019}

O regramento que estipula condições de entrada, permanência e saída de um não nacional no território brasileiro - assim como em qualquer outro Estado - relaciona-se à discricionariedade Estatal, ou seja, está incluída naquilo que convencionalmente se denomina conveniência e oportunidade por parte das Autoridades competentes.

É por esse motivo que os Estados acabam por restringir ou flexibilizar a mobilidade humana de forma a impor a cobrança de taxas de admissão, a quota de imigração ou mesmo a necessidade de apresentar um passaporte - que, inclusive, nem gera direito subjetivo à entrada no Brasil - ${ }^{6}$.

Da mesma forma que o Estado tem a discricionariedade em permitir a entrada do não nacional no país, acolhendo, inclusive, o indivíduo de nacionalidade distinta dos seus, também pode retirar o não nacional do território nacional. Assim, a Lei de Migração estipula em seu capítulo $\mathrm{V}$ as medidas de retirada compulsória (dos arts. 46 à 62).

A lei estipula como sendo espécies de medidas de retirada compulsória a repatriação, a deportação e a expulsão, apenas. Configurando a repatriação na medida de devolução de pessoa em situação de impedimento ao país de procedência ou de nacionalidade (art. 49), enquanto que a deportação consiste na retirada compulsória de pessoa que se encontre em situação migratória irregular em território nacional, decorrido procedimento específico (art.

\footnotetext{
${ }^{6}$ Art. $6^{\circ}$ - O visto é o documento que dá ao seu titular expectativa de ingresso em território nacional. (Lei ${ }^{\circ}$ 13.445/2018).
} 
50) e a expulsão consiste na retirada compulsória de migrante ou visitante do território nacional por questões de segurança nacional ou quando o não nacional atenta contra a tranquilidade pública, conjugada com o impedimento de reingresso por prazo determinado (art. 54).

Como a presente pesquisa analisa a categoria deportação - embora em modalidade nova apresentada por meio de uma Portaria -, é que nos limitaremos a discutir esse instituto em específico.

A marca central da deportação, consiste na retirada do não nacional, quando este encontra-se irregular no país e, após instauração de procedimento administrativo, devidamente notificado, não vem, voluntariamente, se retirar do país.

O fato é que segundo a Lei de Migração, a deportação sempre será precedida de notificação pessoal ao deportado, em que se apresente todas as irregularidades verificadas e o prazo para a regularização não inferior a sessenta dias, podendo ser prorrogado com motivação. A questão, no entanto, é que a deportação é um instituto de retirada compulsória que objeta irregularidade administrativa, e não a prática de crime - que configura situação diferente: expulsão ou extradição.

Guerra (2019, p. 432) pondera que:

[...] A nova lei inovou ao dispor que, mesmo sendo notificado o indivíduo, não ficará impedido de circular livremente no território nacional, devendo, todavia, o imigrante informar seu domicílio e suas atividades. Apenas com o vencimento do prazo para que o mesmo regularize sua situação com o Estado brasileiro, observando-se o princípio constitucional do contraditório e a ampla defesa, é que a deportação poderá ser executada, não excluindo eventuais direitos adquiridos ao deportado, em relações contratuais ou decorrentes da lei brasileira.

Por ser um procedimento administrativo que não objeta investigação de prática de crime, é que se possibilita o prazo para que o não nacional regularize sua permanência no país ou, caso não regularize, voluntariamente se retire do país.

A questão, no entanto, é que a Portaria nº 666/19 utiliza da previsão no $\S 6^{\circ}$ do artigo 50 da Lei de Migração, que possibilita a redução nos casos de enquadramento na situação do inciso IX do art. 45: "IX - que tenha praticado ato contrário aos princípios e objetivos dispostos na Constituição Federal”.

Assim, por meio dessa Portaria, houve uma reconfiguração do prazo, e não apenas uma redução, como institui a própria Lei federal. Nos termos do art. $3^{\circ}$ da Portaria $n^{\circ}$ 666/19:

Art. $3^{\circ}$ A pessoa sobre quem recai a medida de deportação de que trata esta Portaria será pessoalmente notificada para que apresente defesa ou deixe o 
País voluntariamente, no prazo de até quarenta e oito horas, contado da notificacãa. . [grifo nosso]

Não se trata de mera redução, por prática de ato contrário aos princípios e objetivos dispostos na Constituição de 1988. Trata-se da imposição de uma nova modalidade de deportação: a sumária. Essa deportação é completamente diferente da apresentada na Lei Federal, que em nenhum momento se relaciona a prática de delito, mesmo porque, o instituto da deportação limita-se a questão de irregularidade administrativa - a prática de crime pode ensejar hipótese de extradição ou expulsão -.

Não se pode olvidar que a causa da deportação é o não cumprimento dos requisitos necessários para o ingresso regular ou para a permanência do estrangeiro no país. Trata-se, conforme aduziu Mazzuoli (2018) de causa estranha à prática de crime. O que existe, é a situação migratória irregular da pessoa pela não observância das regras estatais sobre ingresso de estrangeiros em seu território, em nada se assemelhando à prática de conduta ilícita.

O novo instituto relaciona-se aqueles nacionais considerados "perigosos ou que tenham praticado ato contrário aos princípios e objetivos dispostos na Constituição Federal”. Ora, a Lei Federal disciplina a hipótese de redução do prazo apenas quando se refere a disciplina do inciso IX do art. 45, que não inclui a situação de periculosidade.

E mais, a Portaria no 666/19 legitima-se na simples afeição de "suspeita" e não de configuração prática irrecorrível, o que acaba encontrando mais alusão, quando se verifica o $\S 1^{\circ}, I V$, do at. $2^{\circ}$ da referida Portaria, que prevê:

$\S 1^{\circ}$ As hipóteses mencionadas nos incisos deste artigo poderão ser conhecidas e avaliadas pela autoridade migratória por meio de:

$[\ldots]$

IV - investigação criminal em curso; e

[...]

O instituto da deportação sumária, portanto, está pautado na inobservância ao princípio da presunção de inocência (esculpido tanto no plano interno - CF/88 e normas infraconstitucionais, quanto no plano internacional) e ao próprio princípio do contraditório e ampla defesa, senão vejamos o porquê.

Diz-se violar o princípio da presunção de inocência, por uma questão lógica: o art. $5^{\circ}$, LVII preceitua que: "ninguém será considerado culpado até o trânsito em julgado de sentença penal condenatória". Ora, se há a prática de suposto crime (terrorismo, organização criminosa armada, tráfico de drogas, pornografia ou exploração sexual infantojuvenil ou 
torcida com histórico de violência em estádios) e não há a sentença penal condenatória transitada em julgado, não há que se falar em situação de irregularidade no país.

O que se observa na Portaria em comento é a incessante necessidade de equiparar institutos totalmente distintos. A expulsão e a extradição têm previsão e regramentos próprios. A deportação, não se refere à prática de crimes, mesmo porque, tal situação não caracteriza, aprioristicamente, hipótese de notificação face a situação irregular do não nacional no território brasileiro.

Observa-se também expressa violação ao princípio da ampla defesa e contraditório, materializados de forma inovadora na Lei da Migração, que com o instituto ilegal da deportação sumária, torna quase que automática a configuração da retirada compulsória do não nacional, face ao exíguo tempo disposto.

A Portaria elenca que o não nacional será notificado para apresentar defesa ou deixar o país no prazo de até quarenta e oito horas. E que na ausência de defensor constituído, a Defensoria Pública da União será notificada para manifestação no prazo de até quarenta horas. Da decisão de deportação caberá recurso, com efeito suspensivo, no prazo de até vinte e quatro horas, contado da notificação do deportando ou de seu defensor.

Ora, somente em um sistema estranho ao brasileiro, esse prazo será cumprido por parte de uma assistência judiciária gratuita. Não se pode olvidar que o sistema da Defesa Técnica Pública é um sistema demasiadamente comprometido com a quantidade de pessoas que precisam dele. Exigir que no prazo de quarenta e oito horas haja manifestação da Defensoria Pública é sinônimo de desconhecimento da práxis jurídica brasileira.

Além disso, segundo tal Portaria, encerrado o prazo para apresentação de defesa, a ausência de manifestação do deportando ou de seu defensor não impede a efetivação da medida de deportação.

Não é demais pontuar, inclusive, que de acordo com a Convenção de Genebra de 1951, há institutos que podem ser utilizados em desfavor dos refugiados, todavia, em caso de ameaça extrema à ordem pública ou à segurança nacional, não dispensando, no entanto, a devida comprovação de que o indivíduo representa de fato grave risco ou à ordem pública ou à segurança nacional. Todavia, tal situação normativa fora totalmente ignorada pela Portaria $666 / 2019$.

Em suma, percebe-se que a referida portaria, além de desconhecer a diferença entre extradição, expulsão e deportação, acaba por tornar automático a configuração de deportação 
sumária, tendo em vista que o procedimento fora elaborado com tempo irreal e com fundamentos ilegais.

\section{CONCLUSÃO}

Diante da exposição de todos os direitos violados através do ato infralegal (Portaria n. 666) introduzido no ordenamento jurídico recentemente, fica claro que as normas internacionais de direitos humanos referentes à migração não devem ser desprezadas, considerando que o Brasil decidiu ser signatário da Declaração Universal dos Direitos do Homem, da Convenção Americana sobre Direitos Humanos (Pacto de San José da Costa Rica) e da Convenção Relativa ao Estatuto dos Refugiados de 1951 (Convenção de Genebra).

O próprio deslocamento já reflete a vulnerabilidade dos migrantes, devendo o Estado garantir a todo migrante a inviolabilidade do direito à vida, à liberdade, à igualdade, à segurança e à propriedade, bem como o direito à liberdade de circulação. Porém, a referida Portaria trabalha com o conceito de suspeito, o que, por si só, fere o princípio da presunção de inocência. Além disso, a forma de enquadramento da "pessoa perigosa" é muito subjetiva.

Porém, ao invés de proteger o não nacional, o Estado rotula sujeitos como pessoas perigosas, desconsiderando o ser enquanto sujeito de direito. A força simbólica exercida através da Portaria n. 666 fere os parâmetros de direito internacional sobre direitos humanos, ao introduzir novas categorias jurídicas, extrapolando sua competência regulamentadora. Além disso, há uma patente violação ao Princípio de Proibição de Retrocesso no âmbito da implementação de direitos sociais.

Sendo assim, a Portaria n. 666 pode ser considerada, de acordo com a perspectiva agambeniana, como uma estratégia de biopolítica da modernidade, na busca de padrões impostos, controle de pessoas e fins de disciplinamento. Isto porque, aqueles que não se enquadrarem no que o Estado espera como sendo o ideal, serão automaticamente enquadrados como pessoas perigosas, sem sequer terem o direito constitucional de defesa resguardando, ofendendo, assim, o princípio constitucional da presunção de inocência. E, o que é mais grave, permitindo critérios subjetivos para averiguar suposto potencial de perigo, o que foge à lógica do Direito Penal que requer critérios concretos e objetivos, até para permitir a defesa.

Não se pode esquecer, que há com a expedição da portaria em comento, de fato, confusão ilógica entre os institutos de retirada compulsória do não nacional em território 
brasileiro. Não se percebe, no conteúdo textual do referido diploma normativo, técnica diferencial entre os institutos expulsão, extradição e deportação. Talvez isso tenha decorrido, exatamente pela simplificação que já é permitida com a instauração da deportação - típica comparada à expulsão e extradição, que tem um maior controle.

Em suma, é o que Casara (2017) já mencionou: vivemos em um estágio de pós democracia, onde a exceção passou, de fato, a ser a regra. A questão é, no entanto, compreendermos se passamos por essa democracia de fato.

Cumpre destacar que no dia 14 de outubro de 2019 foi publicada a Portaria n. 770, revogando a Portaria 666/19. A nova Portaria aumentou o prazo para apresentar defesa ou deixar o país para 5 (cinco) dias, sendo que antes o prazo era 48 (quarenta e oito) horas, bem como aumentou o prazo do recurso da decisão de deportação, que era de 24 (vinte e quatro) horas e passou a ser de 5 (cinco) dias. Embora tenha sido eliminado o termo deportação "sumária", bem como excluído no rol do art. 2 o inciso V "torcida com histórico de violência em estádios", permaneceu o conceito de pessoa perigosa através de mera suspeita, violando, assim, os parâmetros de direito internacional sobre direitos humanos.

\section{REFERÊNCIAS}

AGAMBEN, Giorgio. Estado de exceção. Trad. Iraci D. Poleti. São Paulo: Boitempo Editorial, 2004.

AGAMBEN, Giorgio. Homo sacer: o poder soberano e a vida nua I. Tradução: Henrique Burigo. $2^{\alpha}$ reimpressão. Belo Horizonte: Editora UFMG, 2007.

ASANO, Camila Lissa; TIMO, Pétalla Brandão. A nova Lei de Migração no Brasil e os direitos humanos. Perspectivas, p. 37 - 40, 01 jun. 2017.

BENHABIB, Seyla. A moralidade da migração. O Estado de São Paulo, São Paulo, p. A18, 5 ago. 2012.

BRASIL. Ministério da Justiça e Segurança Pública. Portaria no 666/2019. Dispõe sobre o impedimento de ingresso, a repatriação e a deportação sumária de pessoa perigosa ou que tenha praticado ato contrário aos princípios e objetivos dispostos na Constituição Federal. Diário Oficial da República Federativa do Brasil. Brasília, DF, 26 de julho de 2019, ed 143, seção 1, p. 166.

CASARA, Rubens. Estado pós-democrático: neo-obscurantismo e gestão dos indesejáveis. 1. ed. - Rio de Janeiro: Civilização Brasileira, 2017 
CORREIA, Adriano. A política ocidental é cooriginariamente biopolítica? - Um percurso com Agamben. In: CORREIA, Adriano. Hannah Arendt e a modernidade: política, economia e a disputa por uma fronteira. 1. ed. Rio de Janeiro: Forense Universitária, 2014.

GUERRA, Sidney. Curso de Direito Internacional Público. 12. ed. São Paulo: Saraiva Educação, 2019.

HERRERA FLORES, Joaquín. A (re)invenção dos direitos humanos. Florianópolis: Fundação Boiteux, 2009.

JAKOBS, Günther; MELIÁ, Manuel Cancio. Direito Penal do Inimigo: noções e críticas. Org. e trad.: André Luiz Callegari, Nereu José Giacomolli. 2. ed. Porto Alegre: Livraria do Advogado Editora, 2007.

LOSURDO, Domenico. Contra-história do Liberalismo. 2. ed. São Paulo: Idéias \& Letras, 2006.

MAZZUOLI, Valério de Oliveira. Curso de Direito Internacional Público. 11. ed. Rio de Janeiro: Forense, 2018.

MINISTÉRIO PÚBLICO FEDERAL. Procuradoria Federal dos Direitos do Cidadão. Recomendação No 09/2019/PFDC/MPF. Brasília - DF, 05 de agosto de 2019.

MOYN, Samuel. The last utopia. Cambridge: Harvard University Press, 2010.

NAÇÕES UNIDAS. Convenção Relativa ao Estatuto dos refugiados (Convenção de Genebra), de 28 de julho de 1951.

PIOVESAN, Flávia. Direitos humanos e o direito constitucional internacional. 18. ed., rev. e atual. - São Paulo: Saraiva, 2018a.

PIOVESAN, Flávia. Temas de direitos humanos.11. ed. - São Paulo: Saraiva Educação, $2018 b$.

PIOVESAN, Flávia. Migrantes sob a perspectiva dos direitos humanos. Revista Diversitas, São Paulo, n. 1, ano 1, p. 138-146, mar./set/2013.

RAMOS, André de Carvalho. Curso de Direito Internacional Privado. São Paulo: Saraiva Educação, 2018.

VARELLA, Marcelo. Curso de Direito Internacional Público. Rio de Janeiro: Saraiva, 2018.

VERDÚ, Pablo Lucas. O sentimento constitucional: aproximações ao estudo do sentir constitucional como modo de integração política. Tradução de Agassiz Almeida Filho. Rio de Janeiro: Forense, 2004. 